\title{
Study some of inflammatory indicator with corona patient and relation with chronic disease
}

\author{
Fatima A. abdul jabar ${ }^{1}$,Dhea Sadi Ahmid ${ }^{2}$,Abada Ali lateef ${ }^{3}$ \\ 1,2 Middle Technical University, Baquba Technical Institute, Baquba, Iraq . \\ 3 Iraq ministry of health $\backslash$ Dyala \\ Corresponding author: - fatmaamer@mtu.edu.iq
}

\begin{abstract}
The coronavirus disease epidemic of 2019 (COVID-19) is a scientific, medical, and societal problem.in modern study the investigation of viral pathogenetic pathways, as well as cellular and organ damage, involves the implementation of novel biomarkers. The study showed increased of level of sugar in a significant relationship between patients with COVID-19 and patients with diabetes mellitus at $\mathrm{P}<0.01$, On the other hand, the study demonstrated an increase in the rate of D - dimer in patients infected with Covid - 19, as well as the rate of some inflammatory markers such as acute phase protein(CRP) and WBC at $\mathbf{P}<\mathbf{0 . 0 5}$, The following chemical makers LDH ,ferritin) significantly higher levels in COVID-19-infected individuals than in the Control group. Screening, clinical treatment, and major complication prevention would all benefit from effective biomarkers.
\end{abstract}

Keywords : coronavirus, diabetes mellitus, clinical treatment, D - dimer

\section{Introduction}

Several levels of worry have been raised by the 2019 coronavirus disease pandemic (COVID - 19), which is also known as the coronavirus pandemic of 2019. The unexpected clinical course of the disease complicates the severe acute respiratory syndrome coronavirus 2 and can develop fast with serious and potentially deadly effects (SARS-CoV-2). Scientists urgently demand precise biomarkers linked to the course of COVID - 19 sickness in order to stratify high-risk people. New biomarkers must be developed in order to examine viral pathogenetic pathways and cellular and organ damage $(1,2)$. 
Uncontrolled hyperglycemia has been linked to poor outcomes and death in people with COVID 19 who had diabetes mellitus. An imbalance between clotting factors and fibrinolysis may raise the risk of thrombotic events in diabetics (3).

Effective biomarkers might help in screening, clinical treatment, and averting significant consequences. D - dimer is a result of fibrin breakdown. People with severe illnesses can use it as both a biomarker for thrombosis and a prognostic indication. Since COVID - 19 is a procoagulant disorder, researchers have looked at D - dimer as a biomarker for predicting disease severity (and may be connected to severe effects and death) D - dimer levels appear to be often increased in COVID - 19 people (36-43 percent) (4).

When C-reactive protein (CRP) levels are elevated, it indicates disease progression since it has been connected to lung lesions and recognised as a leading biomarker in liberated studies. IL-6 may be a eminent cancer biomarker. It has also been used as a disease movement watching biomarker in many contexts, and higher levels of IL-6 were shown to be forcefully concomitant with respiratory disappointment in COVID - 19 individuals who were symptomatic $(5,6)$.

During the early stages of the sickness, CRP level has been used as a monitoring biomarker to detect whether the illness is progressing from a mild to severe state. There have been 41 research that indicated CRP to be a leading biomarker, and it has been linked to lung lesions (7) As an established cancer biomarker, High IL-6 levels were associated with respiratory failure in COVID - 19 patients, according to a number of studies using the biomarker as a measure of disease progression. Medical experts can tell if a patient needs mechanical ventilation based on the presence of this biomarker $(8,9)$

Practically every cell in the body has the enzyme LDH, which aids in energy production. Liver disease and interstitial lung disease both have elevated LDH levels, which can be utilised to assess tissue damage. (10).

COVID - 19 patients with various biomarkers are currently being studied to see if any of these indicators might help predict their prognosis. Higher levels of the enzyme Researchers have shown that individuals with different viral infections who have lactate dehydrogenase had poorer outcomes, making it an important biomarker to monitor (11).

COVID - 19 positive individuals were included in our cohort study, and data on epidemiology, clinical care and Patients with severe infection and non-severe infection had their coagulation function obtained and compared. Our cohort study was included in a meta-analysis that looked at the connection between high D - dimer levels and the severe COVID - 19 disease (12)

If you have ITP, you will have petechiae or purpuric rashes, and your platelet count will help determine the diagnosis. To emphasise that many people with ITP do not have bleeding symptoms, a change in nomenclature was advocated lately in favour of "immune thrombocytopenia" (10).

The purpose of current study is to find out how accurate admission D - dimer in COVID - 19 prognosis is and what the appropriate D - dimer cutoff value is for predicting hospital death. 


\section{Materials and method}

In a private Baghdad lab, an experiment was conducted at the AL Canal Medical Laboratory. It was tested on a total of seventy-five different people. Patients who tested positive for COVED-19 virus infection underwent a chest computed tomography scan (CT-Scan) from the (Simens Co.) and 25 healthy volunteers in a comparable age range served as the control group. The study included 52 women and 48 men in total.

The total number of white blood cells, platelets, blood urea, serum creatinine, lactic de hydrogenase (LDH), C-Reactive Protein serum Ferritin D - dimer, and blood group were all assessed in each infected patient and each participant in the control group. A CT scan revealed that the afflicted patient already had the COVED-19 virus (Simens Co.).

The CT-Scan results for the control group showed no signs of the COVED-19 virus.

\section{Samples Collection and Preparation:}

Blood samples were collected from patients and controls using a $10 \mathrm{ml}$ syringe and then divided into three parts: the first part $(5 \mathrm{ml})$ of clotted blood was centrifuged for approximately 15 minutes to obtain a clear serum for biochemical tests, the second part $(1.8 \mathrm{ml})$ of blood was added to a tube with $0.2 \mathrm{ml}$ sodium citrate and centrifuged for approximately 10 minutes to obtain a clear plasma for only the Ddimer test.

\section{Procedures:}

Blood urea, serum creatinine, random blood sugar, C- reactive protein, and lactic dehydrogenase (LDH) were all evaluated automatically utilising a French-made SELECTRA PRO M Lite completely automatic biochemistry analyzer and commercial ELITECH clinical system kits. Counting of white blood cells and platelets was performed using a Rayto brand five-part open system haematology analyzer. And the D - dimer test was calculated in serum utilising a Japanesemade Tosoh AIA -900 automated immunoassay analyzer.

\section{Results and Discussion}

Deaths due to COVID - 19 are associated with diabetes mellitus and a person's specific level of hyperglycemia. Diabetes is more likely to occur in COVID - 19 patients, as demonstrated in the table and figure (1). It is probable that the effects of COVID - 19 on diabetes mellitus might be linked to changes in Inflammation, immunological status changes, and renin-angiotensinaldosterone system activation all affect glucose homeostasis (RAAS). People with diabetes are more likely to get bacterial, mycotic, parasitic, or viral illnesses. (25) A diabetes diagnosis was shown to be associated with a threefold increase in mortality risk in the study (26). 


\section{Covid - 19 patients}

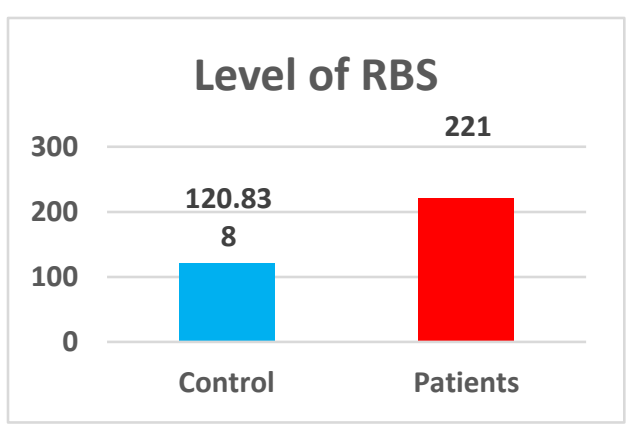

Table (1) the level blood sugar in

\begin{tabular}{|l|l|}
\hline Group & Mean \pm SE \\
\hline Control & $120.838 \pm 4.092$ \\
\hline Patients & $221 \pm 7.989$ \\
\hline $\begin{array}{l}\text { LSD } \\
\text { value }\end{array}$ & $18.499 * *$ \\
\hline P-value & 0.0001 \\
\hline$* * \mathrm{P}<0.01$ \\
\hline
\end{tabular}

Figure 1 the level blood sugar in Covid - 19 patients

Table(2) Effect of age on levels of D - dimer and RBS in Covid - 19 patientes

\begin{tabular}{|l|l|l|l|}
\hline \multirow{2}{*}{ Age group/year } & Mean \pm SE & \\
\cline { 3 - 4 } Control & Less than 40 & D.dimer & RBS \\
\cline { 2 - 4 } & More than 40 & $270.85 \pm 22.716$ & $123.05 \pm 5.513$ \\
\hline \multirow{2}{*}{ Patients } & Less than 40 & $255.40 \pm 26.551$ & $118.04 \pm 6.038$ \\
\cline { 2 - 4 } & More than 40 & $1444.21 \pm 224.355$ & $212.83 \pm 9.153$ \\
\hline LSD value & $2896.00 \pm 851.174$ & $227.27 \pm 12.263$ \\
\hline $\mathrm{P}$-value & $2091.656^{* *}$ & $37.3202^{* *}$ \\
\hline$* * \mathrm{P}<0.01$ & 0.0001 & 0.0001 \\
\hline
\end{tabular}

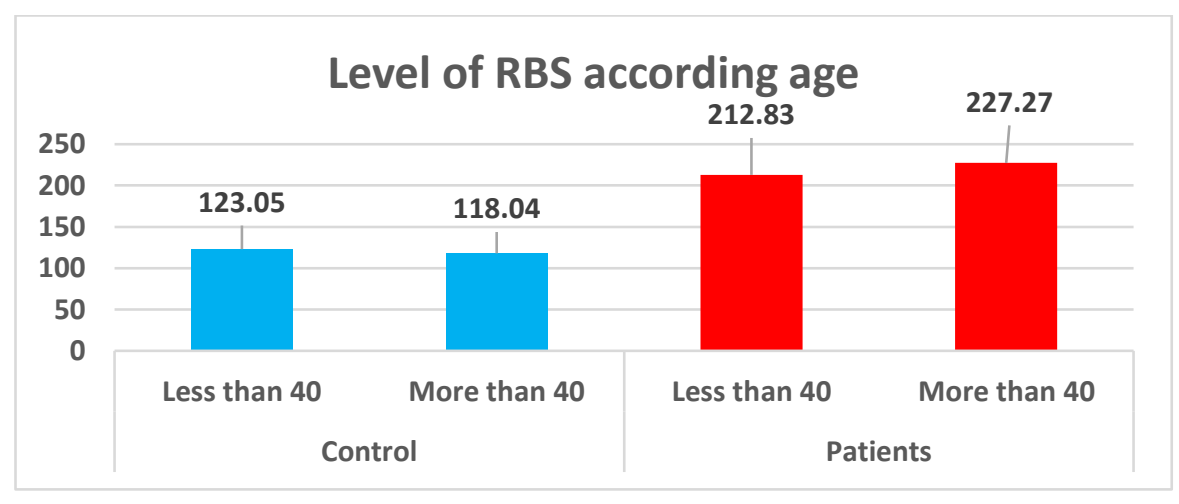

\section{figure 2 Effect of age on levels of D - dimer with Covid - 19}

Covid - 19 patients with signs of chronic diabetes had a greater infection rate than those under 40, according to the findings in the table and figure 3. People with diabetes who are infected with viruses may have an increase in irritation or internal swelling as a result of the infection. This may 
also be due to blood sugar levels that are higher than normal, and the discomfort that results from this may lead to more issues.

Diabetes is more common in those over 40 because: There is usually no polyuria or polydipsia in old persons due to the renal edge for glucose increasing with age and thirst components being obstructed in the elderly (30)

Researchers found that individuals infected with Covid - 19 had higher D - dimer levels than those without an acute infection, and these values rose with increasing age in the study's table and figure $(3,4)(28,29)$ Biomarkers for thrombotic diseases, including D - dimer, are commonly employed to look for the destruction of fibrin, whose levels rise with age and during pregnancy. When the severity of community-acquired pneumonia is elevated, the D - dimer level rises. D - dimer has been discovered as a possible prognostic predictor in COVID - 19 patients following the flare-up of the COVID - 19 epidemic. D - dimer levels on the patient's admission day can be used to predict disease severity, according to several research. D - dimer has been identified in COVID - 19 patients as a potential prognostic indicator. D - dimer levels on the day of admission have been shown in several studies to be predictive of disease severity.

Table 3 level of D - dimer in Covid - 19

patients

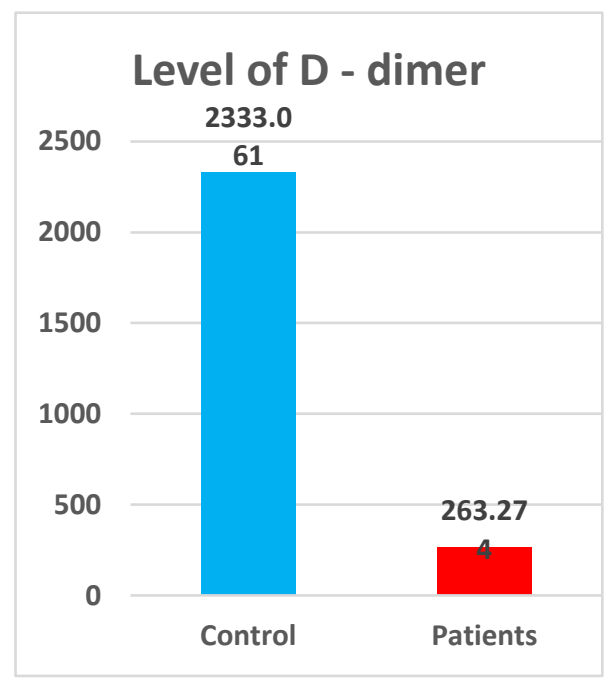

\begin{tabular}{|l|l|}
\hline Group & Mean \pm SE \\
\hline Control & $\mathbf{2 3 3 3 . 0 6 1} \pm \mathbf{1 7 . 2 8}$ \\
\hline Patients & $\mathbf{2 6 3 . 2 7 4} \pm \mathbf{5 3 4 . 5 4 0 2}$ \\
\hline $\begin{array}{l}\text { LSD } \\
\text { value }\end{array}$ & $\mathbf{1 0 4 0 . 1 4 2} * *$ \\
\hline P-value & $\mathbf{0 . 0 0 0 1}$ \\
\hline$* * P<0.01$ & \multicolumn{2}{|l}{} \\
\hline
\end{tabular}

\section{Figure3 level of $d$ - dimer in Covid - 19 patient}

Septic shock is characterised by severe D - dimer elevation, which is also a mortality predictor in coronavirus-2019 (COVID - 19) disease. D - dimer is a measure of how much cross-linked fibrin is broken down by plasmin, causing intravascular coagulation. An increase in the use of thromboelastometry to track systemic fibrinolysis after liver transplantation and major trauma has been reported (27); the emergence of COVID19 illness has been associated to aberrant coagulation function, specifically elevated D - dimer levels. 


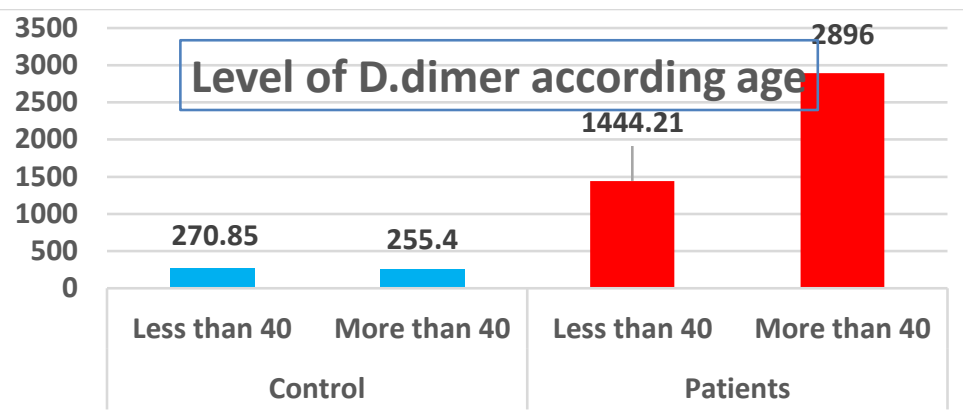

Figure 4 Figure 3 level of $\mathbf{d}$ - dimer according of age in Covid - 19 patients

\section{Effectiveness of indicators (LDH,CRP) in the prediction of severity of COVID - 19}

This study demonstrated table and figure(4), The increase of LDH For patients with Covid - 19 infection, especially in acute Cases, showing tissue/cell damage and accepted as a typical indicator of tissue/cell injury, suggesting viral contamination or lung damage, such as pneumonia caused by SARS-CoV-2 (32,33).

Table (4) level of LDH in Covid - 19 patients

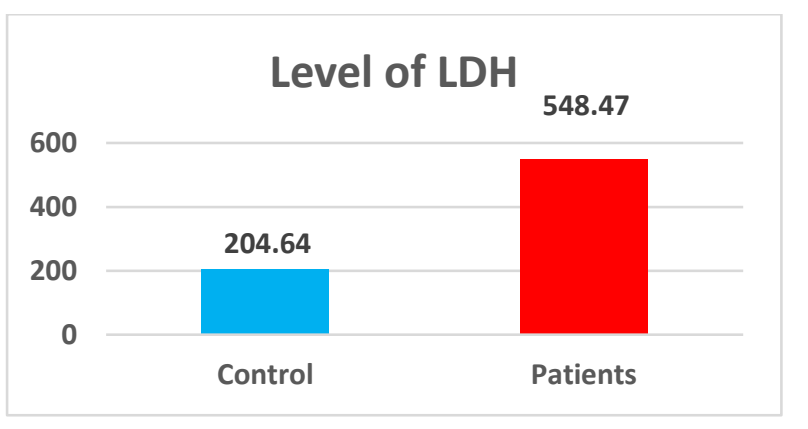

\begin{tabular}{|l|l|}
\hline Group & Mean \pm SE \\
\hline Control & $204.64 \pm 12.271$ \\
\hline Patients & $548.47 \pm 85.462$ \\
\hline LSD value & $484.633 * *$ \\
\hline P-value & 0.0001 \\
\hline & \\
$* * \mathrm{P}<0.01$ & \\
\end{tabular}

Figure(4) level of LDH in Covid - 19 patients

The findings of our pooled analysis show a link between higher CRP levels and poorer outcomes in COVID - 19 patients (table, figure (5)). Previous study has proven that changed levels of various blood indicators may be connected with the severity and mortality of individuals with COVID19. When the liver produces CRP, it's an early warning sign of infection and inflammation (33). 
Table (5) level of LDH in COVID - 19 patients

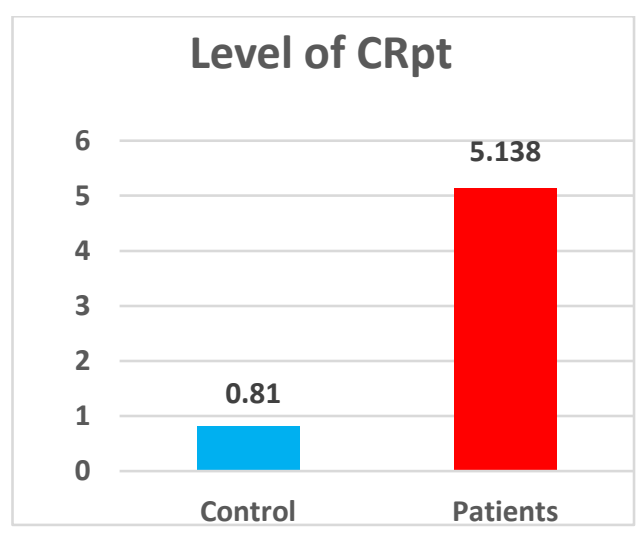

\begin{tabular}{|l|l|}
\hline Group & Mean \pm SE \\
\hline Control & $\mathbf{0 . 8 1 0} \pm 0.019$ \\
\hline Patients & $\mathbf{5 . 1 3 8} \pm 1.466$ \\
\hline LSD value & $4.354 *$ \\
\hline P-value & $\mathbf{0 . 0 4 1}$ \\
\hline *P $<\mathbf{0 . 0 5}$ & \\
\hline
\end{tabular}

\section{Table (5) level of LDH in Covid - 19 patients}

The findings about of our pooled investigation illustrate an affiliation between hoisted LDH values and more regrettable results in patients with COVID - 19 (32)

The results exploited table and figure 6, A slight increase in the rate of loud platelets for patients with Covid - 19, Many viruses, notably the hepatitis B and C viruses (HBV and HCV), have been linked to platelet accumulation (33).

Table (6) level of platlate in Covid - 19 patients

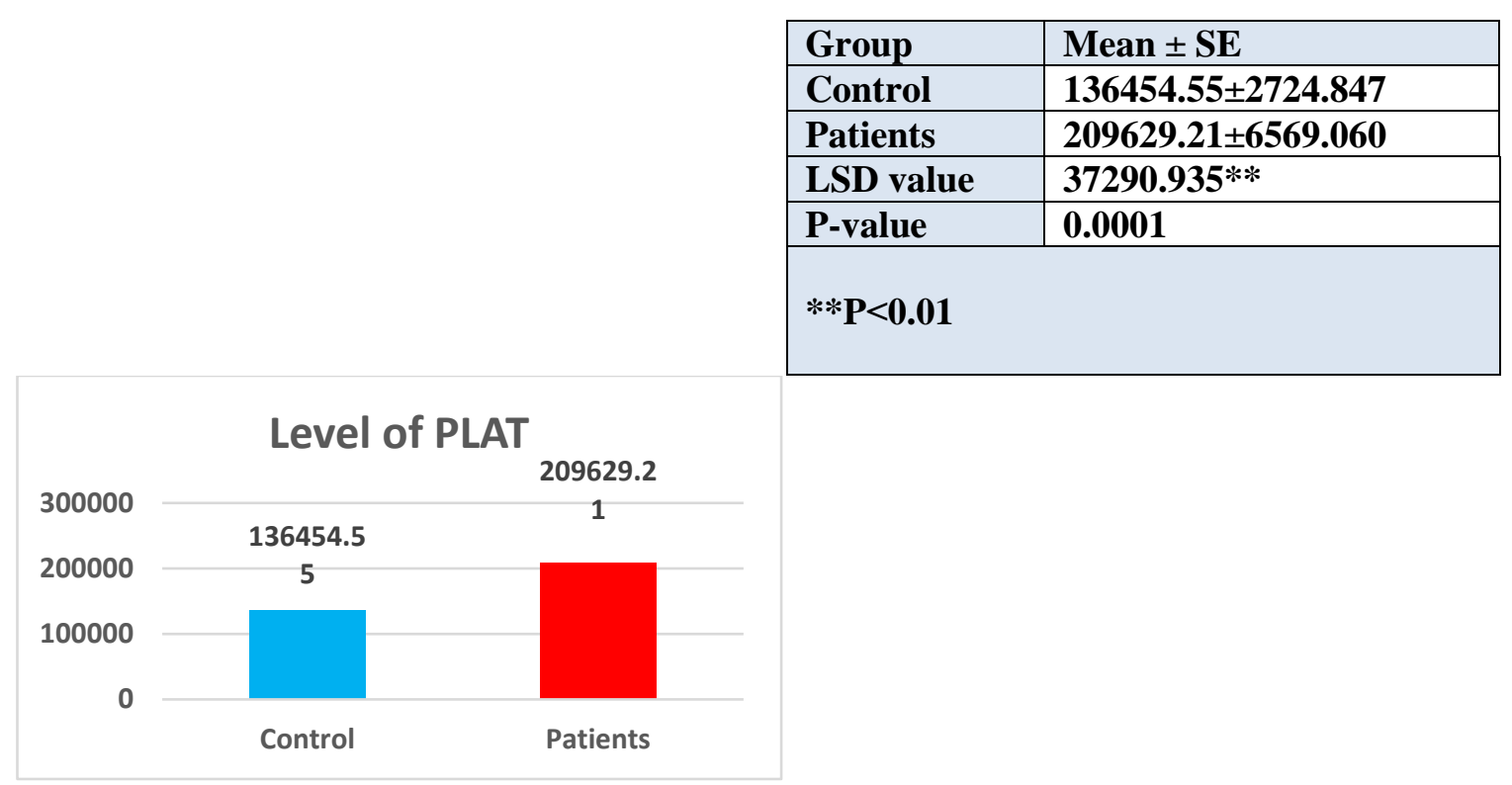

\section{Table (6) level of platlate in Covid - 19 patients}

Previous studies showed an increase in the thrombocytopenia rate in acute and moderate cases of people infected with In addition to infections with COVID - 19, immune thrombocytopenic purpura (ITP) can arise as a result of exposure to COVID - 19 (34) 


\section{Effectiveness of indicators (serum ferritin) in the prediction of severity of COVID - 19}

In this work, we looked at the aspects of iron homeostasis in COVID - 19 patients., table and figure (7) exhibited that serum ferritin levels were greater in COVID - 19 patients than in healthy controls ( $\mathrm{p}<0.001$ ), implying that they might be utilised as biomarkers to envisage the sternness of COVID - 19 disease.

We investigated the blood routine biomarkers from COVID - 19 patients in this research table and figure (6), and found that WBC were considerably lower in COVID - 19 patients than in healthy controls. The researchers (35) discovered that individuals with severe COVID - 19 had substantially higher levels of leukopenia, thrombocytopenia, and C-reactive protein $(\mathrm{p}<0.05)$. After a viral pneumonia infection, a significant number of cytokines are released, resulting in an increase in the marginal granulocytes in white blood cells and a decrease in circulating pools. It was discovered that eosinophils dropped dramatically, if not completely eliminated, and that eosinophils may suggest a bad prognosis (36).

Table (7) level of ferritin in Covid - 19 patients

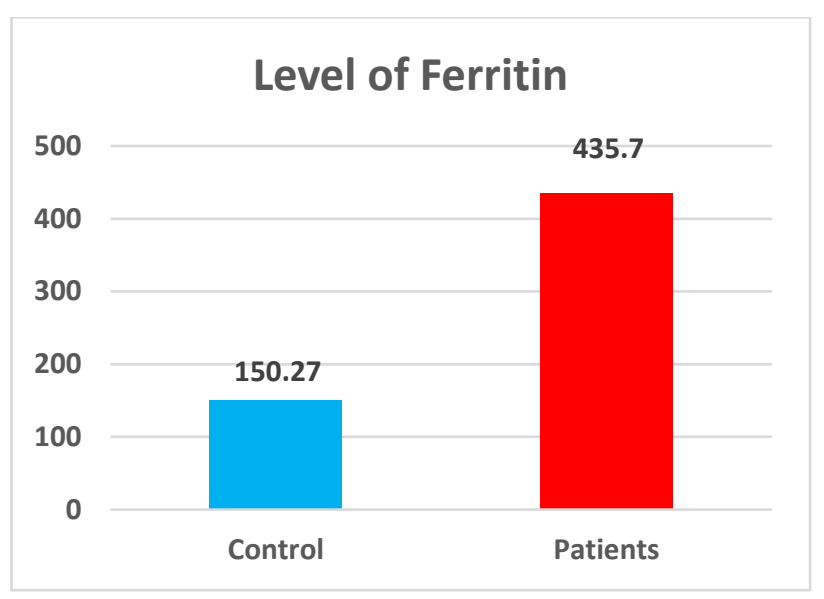

\begin{tabular}{|c|c|}
\hline Group & Mean \pm SE \\
\hline Control & $\mathbf{1 3 6 4 5 4 . 5 5} \pm 2724.847$ \\
\hline Patients & $\mathbf{2 0 9 6 2 9 . 2 1 \pm 6 5 6 9 . 0 6 0}$ \\
\hline LSD value & $37290.935 * *$ \\
\hline P-value & $\mathbf{0 . 0 0 0 1}$ \\
\hline \multicolumn{2}{|c|}{$* * \mathbf{P}<0.01$} \\
\end{tabular}

Table (7) level of ferritin in Covid - 19 patients

\section{Conclusion}

High blood sugar levels are linked to diabetes, which can heighten the cytokine storm that has been linked to extreme cases of Covid - 19. DM issues and co-morbidities are more frequent among senior diabetics than in their younger counterparts. It is now commonly acknowledged that older age, diabetes, and hypertension all increase the morbidity and mortality of patients with COVID 19.

Finally, our findings suggest that D - dimer may be used to identify high-risk people and is an precise biomarker for predicting mortality in COVID - 19 patients. 


\section{References}

1- Coronavirus COVID - 19 (2019 nCoV) bda7594740fd40299423467b48e9ecf6 [Internet]. [cited 2020 Sep 13]. Available from:-

2- Wu C., Chen X., Cai Y., Xia J., Zhou X., Xu S. Risk factors associated with Acute respiratory distress Syndrome and death in patients with coronavirus disease 2019 pneumonia in Wuhan, China. JAMA Intern Med. 2020;180:934-943. [PMC free article] [PubMed] [Google Scholar]

3- Bin S.Y., Heo J.Y., Song M.S., Lee J., Kim E.H., Park S.J. Environmental contamination and viral shedding in MERS patients during MERS-CoV outbreak in South Korea. Clin Infect Dis. 2015;62:755-760. [PMC free article] [PubMed] [Google Scholar]

3- Hunter C.A., Jones S.A. IL-6 as a keystone cytokine in health and disease. Nat Immunol. 2015;16:448-457. Erratum in: Nat Immunol 2017;18:1271. [PubMed] [Google Scholar]

4- Wang L. C-reactive protein levels in the early stage of COVID - 19. Med Mal Infect 2020;50:332-4. [PMC free article] [PubMed] [Google Scholar]

5- Dingerdissen HM, Bastian F, Vijay-Shanker K, et al. . OncoMX: a knowledgebase for exploring cancer biomarkers in the context of related cancer and healthy data.JCO Clin Cancer Inform 2020;4:210-20.

7- Hunter C.A., Jones S.A. IL-6 as a keystone cytokine in health and disease. Nat Immunol. 2015;16:448-457. Erratum in: Nat Immunol 2017;18:1271. [PubMed] [Google Scholar]xcf

8- Wang L. C-reactive protein levels in the early stage of COVID - 19. Med Mal Infect 2020;50:332-4. [PMC free article] [PubMed] [Google Scholar]

9- Herold T., Jurinovic V., Arnreich C. Elevated levels of interleukin-6 and CRP predict the need for mechanical ventilation in COVID - 19 [published online ahead of print, 2020 May 18] J Allergy Clin Immunol. 2020

10- Uchide N, Ohyama K, Bessho T, Toyoda H. Lactate dehydrogenase leakage as a marker for apoptotic cell degradation induced by influenza virus infection in human fetal membrane cells. Intervirology. 2009;52(3):164-73.

11- Pan F, Ye T, Sun P, Gui S, Liang B, Li L, et al. Time course of lung changes on chest CT during recovery from 2019 novel coronavirus (COVID - 19) pneumonia. Radiology. 2020;295(3):715-21.

12- Wu J, Liu J, Zhao X, Liu C, Wang W, Wang D, Xu W, Zhang C, Yu J, Jiang B,et al. Clinical Characteristics of Imported Cases of COVID - 19 in Jiangsu Province: A Multicenter Descriptive Study. Clin Infect Dis. 2020;29:ciaa199. 
20-Tao R.J., Luo X.L., Xu W. Viral infection in community acquired pneumonia patients with fever: a prospective observational study. J Thorac Dis. 2018;10(7):4387-4395. [PMC free article] [PubMed] [Google Scholar]

25- Hodgson K, Morris J, Bridson T, Govan B, Rush C, Ketheesan N. Immunological mechanisms contributing to the double burden of diabetes and intracellular bacterial infections. Immunology. 2015;144(2):171-185.

26- Booth CM, Matukas LM, Tomlinson GA, et al. Clinical features and short-term outcomes of 144 patients with SARS in the greater Toronto area. JAMA. 2003;289(21):2801-2809

27- Muller MC, Meijers JC, Vroom MB. Utility of thromboelastography and/or thromboelastometry in adults with sepsis: A systematic review. Crit Care. 2014;18:R30. [PMC free article] [PubMed] [Google Scholar]

28- Querol-Ribelles JM, Tenias JM, Grau E, Querol-Borras JM, Climent JL, Gomez E, et al. Plasma $\mathrm{D}$ - dimer levels correlate with outcomes in patients with community-acquired pneumonia. Chest. 2004;126: 1087-1092. pmid:15486368

29- Zhou F, Yu T, Du R, Fan G, Liu Y, Liu Z, et al. Clinical course and risk factors for mortality of adult inpatients with COVID - 19 in Wuhan, China: a retrospective cohort study. Lancet. 2020;395: 1054-1062. pmid:32171076 30-Chau D, Edelman SV. Clinical management of diabetes in the elderly. Clin Diabetes. 2001;19:172-5. [Google Scholar

31- Ali N. Is SARS-CoV-2 associated with liver dysfunction in COVID-19 patients? Clin Res Hepatol Gastroenterol. 2020. 10.1016/j.clinre.2020.05.002

32 Wang G, Wu C, Zhang Q, et al. C-reactive protein level may predict the risk of COVID-19 aggravation. Open Forum Infect Dis. 2020;7(5). 10.1093/ofid/ofaa153 -

33-Y. Zhu, Z. Du, Y. Zhu, W. Li, H. Miao, Z. Li. Evaluation of organ function in patients with severe COVID - 19 infections. Med Clin (Barc), (2020),

34-Boyer Chammard T, Schepers K, Breurec S, Messiaen T, Destrem AL, Mahevas M, Soulillou A, Janaud L, Curlier E, Herrmann-Storck C, Hoen B. Severe thrombocytopenia after Zika virus infection, Guadeloupe, 2016. Emerg Infect Dis. 2017;23(4):696-698. doi: 10.3201/eid2304.161967.

35- Qin C, Zhou L, Hu Z, Zhang S, Yang S, Tao Y, Xie C, Ma K, Shang K, Wang W, Tian DS. Dysregulation of immune response in patients with coronavirus 2019 (COVID - 19) in Wuhan, China. Clin Infect Dis. 2020;71(15):762-768. doi: 10.1093/cid/ciaa248. [PMC free article] [PubMed] [CrossRef] [Google Scholar]

36-Guan WJ, Ni ZY, Hu Y, et al. Clinical characteristics of coronavirus disease 2019 in China. $N$ Engl J Med. 2020;382(18):1708-20. 